\title{
Discussion: information policy
}

\section{Tony Cawkell}

The Government appears to be jumping on the bandwagon of distance learning, while the evidence about its effectiveness is controversial. Investigate effectiveness first. If it is effective, then spend money on technology.

\section{Christine Borgman}

There has been no mention of the Fifth Framework and other international initiatives. How do the speakers suggest we link into these?

\section{Mel Collier}

The Fifth Framework was used to help the Library and Information Commission develop its framework.

\section{Derek Law}

The problem with developing EU links is that the European Commission are only willing to have discussions at project level not programme level. The difficulty with developing links with trans-Atlantic programmes is that they need matching funds.

\section{Margaret Haines}

There has been a useful discussion with the Department of Trade and Industry about setting up working groups, and they are looking for recommendations. The Department of Culture, Media and Sport is also promoting the Library and Information Commission. The Department for Education and Employment is also keen to play an active role in setting up the information policy, and was surprised when it learnt about the areas in which the Library and Information Commission is involved, as there are a lot which are of interest to them.

\section{Peter Burnhill}

Other EU countries are wishing to use Fifth Framework to develop their own information policy. Do the speakers feel we have exploited the Fifth Framework strategy and used it as the lever we should?

Charles Oppenheim

It all comes back to the fact that EU links are project led rather than programme led, and this puts up barriers.

\section{Stephen Robertson}

With reference to the co-ordinating role of Library and Information Commission, there appears to be a notable absence of the EPSRC from the list of co-operating bodies mentioned. Is there a barrier?

\section{Margaret Haines}

There has been a meeting with EPSRC already; they were amazed to find out what the Library and Information Commission is doing, and there is an intention to work together. 


\section{Stephen Robertson}

There is a very real danger in looking at research and expecting to see working applications of the research in a very short time scale. An example is the OKAPI project work, which only began to make an impact some six years later. The reasearch for OKAPI itself relied on earlier research going back to the 1970s. Another example is TREK, which was the grandchild of a Cranfield Project supported by the NSF in the 1960s. The intermediate stage of this work was a project funded by the British Library.

There is a need to reinforce when you do blue sky research, or research aimed at a particular end, as there is very rarely a linear progression.

\section{Derek Law}

One of the successes of BLRIC is in creating a cadre of researchers and an agenda to move research forward.

\section{Sandra Ward}

What form do Derek Law and David Russon see co-operation taking and what do they think are the key factors in bringing it about?

\section{Derek Law}

There is a need to thrash out a common agenda, with British Library looking outwards again. I feel that the British Library agenda has been more publishing focused rather than Library and Information Science focused. There is a need to work together.

\section{David Russon}

The critical issue is to decide amongst institutions first who should take the lead in ensuring that we can access information worldwide now, and secondly what we should archive and who should be responsible for ensuring that this is done.

\section{John Sumsion}

One of the successes of the British Library has been its document delivery from Boston Spa. Is delivery in future going to concentrate on electronic delivery?

\section{David Russon}

It depends on what you mean by electronic delivery. For example, items may be stored in digital format rather than in paper stores at Boston Spa, but may have to be provided to the end user in print format. British Library is limited by publisher agreements, and licences dictate what can be done.

\section{Derek Law}

This is a huge topic in its own right. Access to whole community of scholarly publishing may change hugely. 